RESEARCH PAPER

\title{
Adolescent smoking decline during California's tobacco control programme
}

\author{
J P Pierce, M M White, E A Gilpin
}

Tobacco Control 2005;14:207-212. doi: 10.1136/tc.2004.010116

See end of article for authors' affiliations

Correspondence to: John P Pierce, PhD, Cancer Prevention and Control Program, Cancer Center, University of California, San Diego, La Jolla, Ca 92093-0645, USA; ippierce@ucsd.edu

Received

23 September 2004

Accepted 23 March 2005
Objective: California's comprehensive tobacco control programme was 13 years old in 2002; by then, children entering adolescence at the start of the programme were young adults. This study examines whether adolescent smoking declined over this period, whether any decline carried through to young adulthood, and whether it was specific to California.

Setting and participants: Most data were from the 1990-2002 California Tobacco Surveys (CTS) (adolescents 12-17 years, $>5000$ /survey, young adults 18-24 years, $>1000 /$ survey). Additional data were from the national 1992/93-2001/02 Current Population Survey (CPS) (young adults 18-24 years, $>15000 /$ survey).

Results: Over the 13 year period in California, ever puffing declined by $70 \%$ in $12-13$ year olds, by $53 \%$ in 14-15 year olds from 1992-2002, and by 34\% in 16-17 year olds from 1996-2002 (CTS). As noted, the decline commenced progressively later in each older group. Smoking experimentation (1+ cigarettes) and established smoking (> 100 cigarettes in lifetime) showed similar patterns. Compared to 1990, the percentage of California young adults (CTS data) who ever experimented declined by $14 \%$, with half of the decline from 1999-2002. CPS young adult smoking prevalence (established and now smoke everyday or some days) was constant in the rest of the USA over the entire period, but California showed a recent 18\% decline from 1998/99 to 2001/02.

Conclusions: California's comprehensive programme may have kept new adolescent cohorts from experimenting with cigarettes. Low young adolescent experimentation rates at programme start appeared to carry through to young adulthood, resulting in a recent drop in young adult smoking prevalence in California not observed in the rest of the USA.
C alifornia was the first state in the USA to introduce a statewide tobacco control programme, with ongoing funding guaranteed from a dedicated portion of a voter approved $\$ 0.25 /$ pack cigarette excise tax increase that took effect in 1989. ${ }^{1}$ The master plan for the programme specified that reducing adolescent smoking was a primary goal. ${ }^{2}$ The plan envisioned that this goal would be achieved by implementing a comprehensive tobacco control programme, with additional goals of encouraging smoking cessation among adult smokers and protecting non-smokers from the health dangers of secondhand smoke. It was hypothesised that achievement of these goals would produce changes in the general cultural norms about tobacco use leading to a decrease in adolescent smoking. This comprehensive approach differs from other, more recent approaches that focused solely on adolescents, such as the Florida ${ }^{3}$ and American Legacy Foundation "Truth" campaigns. ${ }^{4}$ While the California programme has been associated with both lower per capita cigarette consumption and adult smoking prevalence, ${ }^{5-7}$ evidence for a sustained effect on smoking initiation has not been assessed.

There are several ways that California's programme could influence smoking behaviour in new young adolescent cohorts. First, it could delay or prevent any experimentation with cigarettes. Successful school prevention programmes throughout the 1970s and 1980s were unable to prevent experimentation, but they did manage to delay it from the early to older adolescent years. ${ }^{8}$ A number of investigators have noted that the earlier people initiate smoking, the more likely they are to eventually become high consumption smokers and experience greater difficulty in quitting. ${ }^{9-12}$ While preventing any experimentation would be the optimal outcome, delaying it would still result in long term health benefits for the population, since late initiators might not smoke as much and be more likely to successfully quit. Also, the programme might reduce the likelihood that an experimenter would become an established smoker.

Although there were wide yearly fluctuations in funding for California's programme between 1990 and 2002, on average it spent just under $\$ 3$ per person per year to achieve its goals. ${ }^{13}{ }^{14}$ From its inception, the programme provided separate budgets for state directed activities through the Department of Health Services (DHS), as well as a programme specifically for schools directed by the Department of Education (DE). In addition to its multiple community based programme efforts to curb tobacco use, the DHS efforts supported an ongoing anti-tobacco mass media campaign. Both components focused on the following major areas: (1) reducing exposure to secondhand smoke, (2) reducing underage access to tobacco products, (3) promoting smoking cessation, and (4) countering the marketing strategies of the tobacco industry. Legislation to enable the California Tobacco Control Program required that all schools become tobacco-free by 1996. The DE programme initially focused on funding curricula for all elementary and middle schools based on attendance. Starting in 1995, prevention and smoking cessation education funding for high schools was available on a competitive basis; $66 \%$ of all high schools were supported by 1996/97. A requirement for a high school to receive funding support was that it immediately implement a smoke-free policy. Elementary and middle schools

Abbreviations: CPS, Current Population Survey; CTS, California Tobacco Surveys; DE, Department of Education; DHS, Department of Health Services; MSA, Master Settlement Agreement 
have had smoke-free policies since 1952; however, enforcement of these policies was likely not rigorous or consistent.

In this article, we present trends for several measures of early smoking behaviour in California adolescents, using data from the successive, cross sectional, population based California Tobacco Surveys (CTS), conducted every three years from 1990 to 2002 . We focus on the age window from 12 to 24 years; age 12 years is the youngest age surveyed in the CTS, and age 24 years is identified in tobacco industry documents as the age after which few people initiate smoking. ${ }^{15}$ The 13 year period for these trends (1990-2002) means that all 12 year olds in 1990 had matured through this initiation window by 2002. Thus, 2002 is the earliest year that we can assess whether the programme not only reduced experimentation among new cohorts of adolescents, but also whether it was associated with a permanent decline in ever smoking in those who had matured through the initiation age window. To identify whether young adult trends were unique to California, we compared California data with data from all other states in the USA using the national Current Population Surveys (CPS).

\section{METHODS}

\section{Data sources}

\section{California Tobacco Surveys (CTS)}

The CTS are large cross sectional, random digit dialled, population based household surveys. They were conducted in English or Spanish in 1990, 1992, and every three years between 1993 and 2002, as part of the California Tobacco Control Program evaluation. ${ }^{1}$ The detailed survey design and methods are described elsewhere. ${ }^{16}$ In brief, samples of telephone area code/prefixes are drawn within each of 18 regions in California. In each survey, an adult (18+ years) in each household enumerated all household residents, providing demographic and smoking status information on each.

In all years except 1999, all adolescents $12-17$ years of age were selected for an approximately 25 minute interview on smoking related behaviours and attitudes. The 1999 survey design specified that one adolescent be randomly selected for an interview if more than one was enumerated; other adolescents in the household were not eligible and they were not interviewed if a completed interview was not obtained for the adolescent selected. After obtaining consent from a household adult, the interviewer scheduled an appointment to call back and interview adolescents several days later. Except for the 2002 survey, in which all young adults 18-29 years of age were selected for an extended interview, all adults 18 years of age and older were randomly selected, with the selection probability higher for an extended interview if someone was reported to have smoked in the past five years.

Table 1 shows the number of adolescents and young adults interviewed and their completion rates for each CTS. A minimum of 5040 adolescents aged 12-17 years were interviewed in each year, and completed interviews were obtained for $67-80 \%$ of those selected. The number of young adults 18-24 years varied, from about 1000 in 1992 to nearly 6000 in 2002, with completed interview rates of $61-68 \%$. The 1992 survey was small because of budgetary constraints. Over the 13 year period, there has been a decline in household contact rates for telephone surveys in the USA, ${ }^{18}$ for reasons such as the proliferation of dedicated phone lines for computers and fax machines, and increased call screening to avoid telemarketing. A response rate decline has also been observed in other surveys, such as the CPS, where the interviewer is present in the home. The contact rate decline is not specific to California, and its impact on estimates of smoking prevalence has been investigated in two telephone surveys undertaken in the 1990s in two states, California and Massachusetts. ${ }^{19}$ The authors concluded that the declining contact rate in telephone surveys does not bias smoking prevalence estimates.

CTS respondents were weighted to obtain appropriate representative estimates of population behaviour. Details of the weighting procedures are available from our website. ${ }^{16}$ Briefly, base weights were computed to account for the probability of household selection. These base weights were then adjusted to population totals (sex, race/ethnicity, education level, and region of the state) to account for non-response.

\section{Current Population Surveys Tobacco Use \\ Supplements (CPS-TUS)}

The national CPS are continuous surveys (over 56000 households/month) conducted by the US Bureau of the Census, primarily to monitor labour force indicators for the civilian non-institutionalised US population aged 15 years and older. The complete CPS methodology is published elsewhere. ${ }^{20}$ A new probability sample is selected every four months, based on a stratified sampling scheme using clusters of four neighbouring households identified from the most recent decennial census, updated building permits, and other sources. All strata are defined within state boundaries, and the sample is allocated among the states so that state specific estimates can be computed.

The CPS included a Tobacco Use Supplement (TUS) for September, January, and May in 1992/93, 1995/96 and 1998/ 99, and June, September, and January in 2001/02. Every effort is made to have each household member 15 years of

Table 1 Adolescent (12-17 years) and young adult (18-24 years) sample characteristics from survey data sources

\begin{tabular}{llllll}
\hline CTS & 1990 & $1992 / 3^{*}$ & 1996 & 1999 & 2002 \\
\hline Adolescents selected for interview & 6604 & 6892 & 8778 & 8069 & 8796 \\
Adolescents with completed interviews & 5040 & 5531 & 6252 & 6090 & 5857 \\
Adolescent completion rate & $76.3 \%$ & $80.3 \%$ & $71.2 \%$ & $75.5 \%$ & $66.7 \%$ \\
Young adults selected for interview & 5509 & 1697 & 3432 & 3255 & 10084 \\
Young adults with completed interviews & 3518 & 1022 & 2478 & 2190 & 5930 \\
Young adult completion rate & $63.9 \%$ & $60.2 \%$ & $72.2 \%$ & $67.3 \%$ & $58.8 \%$ \\
\hline CPS-TUS & & $1992 / 3$ & $1995 / 6$ & $1998 / 9$ & $2001 / 2$ \\
\hline Young adults in households & & 33039 & 26624 & 25463 & 26620 \\
Young adults completing TUS & & 22927 & 16835 & 15419 & 16707 \\
Young adult self response completion rate & & $67.6 \%$ & $63.2 \%$ & $60.6 \%$ & $62.8 \%$ \\
\hline
\end{tabular}

*The 1992 CTS was used for young adults 18-24 years old. The much larger 1993 CTS did not include a question on ever smoking in the adult interview, but adolescent data from the 1993 CTS included all the relevant early smoking behaviour questions.

CPS-TUS, Current Population Surveys Tobacco Use Supplement; CTS, California Tobacco Surveys. 
age and older respond to the TUS during the initial household visit. In someone is not available, an adult proxy respondent reports smoking status, and a telephone TUS interview is scheduled for the absent household member. Despite up to three attempts to contact absent household members, not everyone is reached. In this study, we only considered self reported smoking status.

The CPS-TUS have a separate set of survey weights for self respondents. These are computed using a procedure similar to that used for the CTS. Base weights reflect the probability of household selection and are adjusted for non-response using population totals (sex, age, race, education, state).

\section{Smoking behaviour}

Adolescent smoking often starts by trying a few puffs on a cigarette, with many puffers transitioning to smoking a whole cigarette within a short time. ${ }^{21}{ }^{22}$ Some of these experimenters later reach a lifetime consumption level of at least 100 cigarettes that will define them as an adult ever smoker $^{21}$ or as having attained an established smoking behaviour. ${ }^{23}$ Among those who reach this level, half will smoke for more than 16-20 years. ${ }^{24}$

\section{Adolescent smoking measures}

The CTS first asked adolescents, "Have you ever smoked a cigarette?". Those answering "no" were further probed, "Have you ever tried or experimented with cigarette smoking, even a few puffs?". Those answering "yes" to the first question were asked, "Have you smoked at least 100 cigarettes in your life?". We define "puffers" as those who
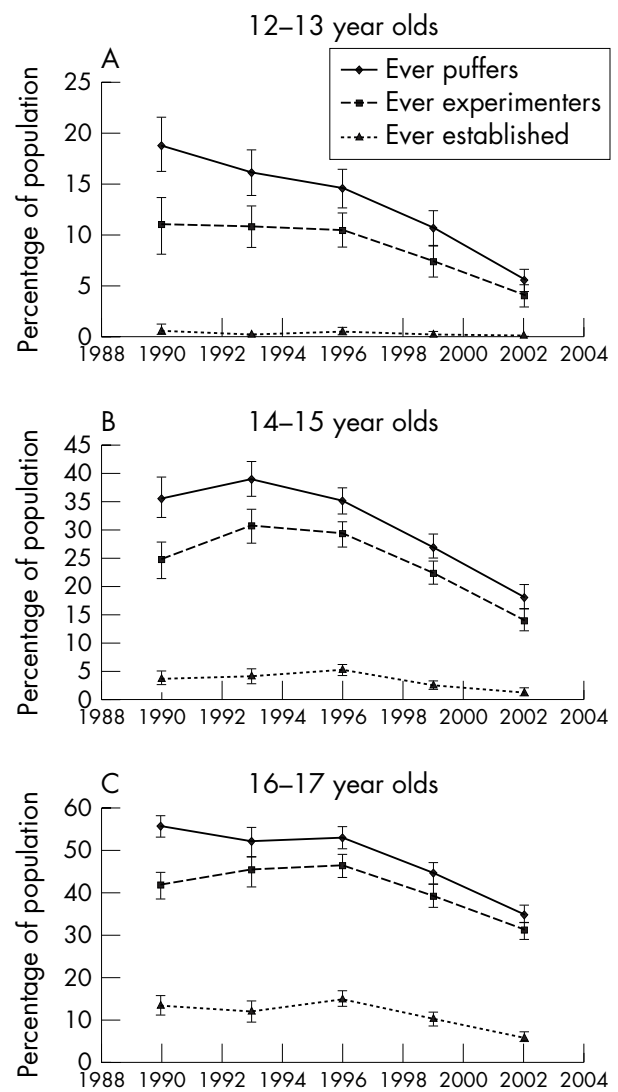

Figure 1 California Tobacco Survey trends in the prevalence of ever puffers (includes puffers, experimenters, and established smokers), ever experimenters (includes experimenters and established smokers) and established smokers among 12-13 year old adolescents (panel A), 1415 year old adolescents (panel B), and 16-17 year old adolescents (panel C). Confidence intervals (95\%) are shown. denied smoking a cigarette, but who answered "yes" to the puffing question. "Experimenters" are defined as those who answered "yes" to the first question, but who denied having smoked at least 100 cigarettes. We define "established smokers" as those who indicated that they had smoked at least 100 cigarettes in their lifetime. Finally, "current adolescent smokers" are defined as anyone who gave an answer other than "none" to the question, "Think about the last 30 days. On how many of these days did you smoke?".

Young adults (18-24 years)

None of the CPS and not every CTS sought information on early smoking behaviour, but all the CTS and CPS asked, "Have you smoked at least 100 cigarettes in your entire life?". Those who answered "yes" were then asked, "Do you now smoke cigarettes every day, some days or not at all?". "Current adult smokers" are those who responded "everyday" or "some days". While the CPS surveys people 15 or more years of age, the lack of early smoking behaviour measures restricted our analyses to those age 18-24 years.

\section{Statistics}

The statistical package SuDaaN ${ }^{25}$ was used for variance estimation to allow computation of $95 \%$ confidence intervals for all survey estimates. Both the CTS and CPS come with sets of replicate survey weights for use with jackknife procedures. ${ }^{26}$ The CTS is structured to use the jackknife-n procedure, and the CPS to use Fay's method of balanced replication. ${ }^{25}$

Because California's population differs demographically from the population in the rest of the USA and has changed its racial/ethnic composition in recent years, young adult (1824 years) current smoking prevalence estimates in all years from both the CTS and CPS are standardised to the demographic profile of the 2002 young adult California population (sex, race: non-Hispanic white, Hispanic, other). Preliminary analyses of CTS adolescent data indicated that standardisation was unnecessary, as standardised and simple weighted estimates agreed closely. ${ }^{7}$

\section{RESULTS \\ Adolescent (12-17 years) smoking trends in California}

The top curve in fig lA shows the percentages of the 12-13 year old age group who had ever puffed on a cigarette across each of the survey years from 1990 to 2002. This includes the puffers, experimenters, and the few established smokers in this age group. The gap between the top and next lower curve represents those who had only puffed, and the gap between the middle and lowest curves represents those who had smoked at least one but fewer than 100 cigarettes in their lifetime. The prevalence of ever puffing was highest in 1990 and declined in each survey year over the period indicated. By 2002, the mean (95\% confidence interval) prevalence of ever

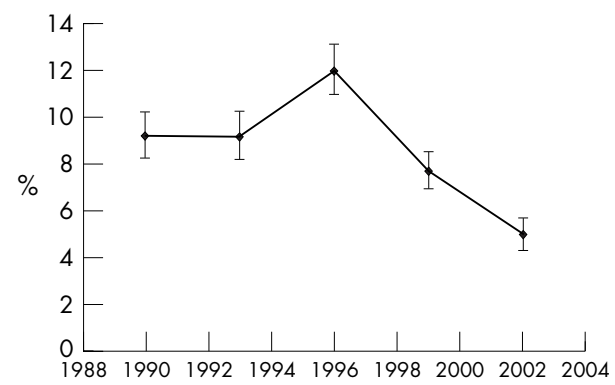

Figure 2 California Tobacco Survey trends in the prevalence of smoking in the past 30 days (current smoking) in adolescents 12-17 years of age. Confidence intervals (95\%) are shown. 
puffing was $5.6(1.1) \%$, a decline of $70 \%$ from the level in $1990(18.9(2.7))$. The percentage of those ever experimenting (experimenters and established smokers) also declined over this period, from $11.0(2.7) \%$ in 1990 to 4.1 (1.1)\% in 2002 , or by $63 \%$. Fewer than $1 \%$ of adolescents 12 and 13 years of age were established smokers in any survey year, and this percentage was only $0.1(0.1) \%$ in 2002 .

By 14-15 years of age (fig 1B), many more adolescents have gained smoking experience (note the different scale to the vertical axis). In contrast to the $12-13$ year olds, this age group showed a slight increase in the prevalence of ever puffing between 1990 and 1993, with a steady decline thereafter through 2002. From the peak in 1993 (39.3 $(3.0) \%)$, the prevalence of ever puffing declined by $53 \%$ to its level in $2002(18.4(2.2) \%)$. This was about the same as the level for 12-13 year olds in 1990. Both ever experimentation and established smoking showed the same general pattern. Experimentation declined from 24.9 (3.1)\% in 1993 to 14.1 (1.8)\% in 2002, or 43\%. Established smoking declined from $5.4(1.1) \%$ in 1993 to $1.6(0.7) \%$ in 2002 , or by $70 \%$.

The percentage of the 16-17 year old group with any smoking experience was much higher than in the younger age groups (fig $\mathrm{lC}$, note the vertical axis has a different scale). The percentage who had ever at least puffed on a cigarette did not change much between 1990 and 1996, but then declined notably by 1999 , and again by 2002 . From the 1996 level $(52.9(2.6) \%)$, there was a decline of $34 \%$ by 2002 (35.0 (1.9)\%). A similar pattern occurred for ever experimentation, with a 33\% decline from 1996 (46.4 (2.7)\%) to 2002 (31.0 (1.9)\%). The rate of established smoking was also highest in 1996 (15.0 (1.7)\%), with a notable decline from 1996 to 1999 and a smaller decline between 1999 and 2002. By 2002, the rate of established smoking for 16-17 year olds (6.1 (1.0)\%) was 59\% lower than in 1996 (15.0 (1.7)\%).

It is to be expected that the trend in 30 day (current) smoking prevalence for 12-17 year old adolescents (fig 2) would follow a pattern similar to the one for established smokers in the oldest age group, as it contributes the largest number of smokers. About $9 \%$ were current smokers in both 1990 and 1993. This percentage increased substantially by 1996, before declining equally as substantially by 1999, and again to $5.0(0.7) \%$ in 2002, a $45 \%$ drop from the 1990 level.

\section{Young adult (18-24 years) smoking trend in California}

Figure 3 shows the trend in ever smoking ( $1+$ cigarettes) prevalence for 18-24 year olds from the CTS. Compared to 1990, the 2002 prevalence of ever smoking was significantly lower by $14 \%$. The decline between 1999 and 2002 was $7.1 \%$ or about half the total decline. This is the first evidence to suggest

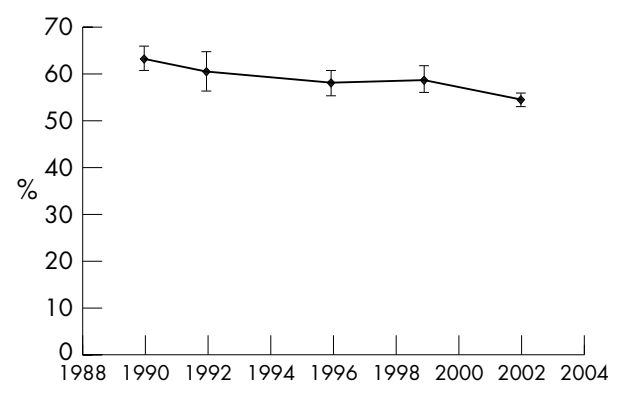

Figure 3 California Tobacco Survey trend in the percentage of young adults (18-24 years) who had ever smoked (1+ cigarettes). The 1992 CTS was used instead of the 1993 CTS, because the relevant question was not asked in 1993. All estimates were standardised to the 2002 California population profile for sex and race/ethnicity (non-Hispanic white, Hispanic, other). Confidence intervals (95\%) are shown.

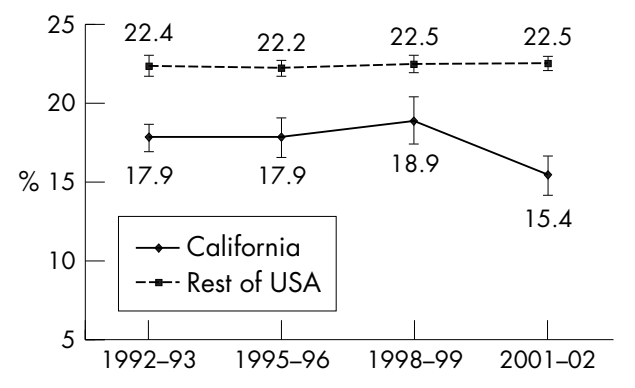

Figure 4 Current Population Survey trends in young adult (18-24 years) smoking prevalence (> 100 cigarettes in lifetime, now smoke everyday or some days) in California and the rest of the USA. All estimates were standardised to the 2002 California population profile for sex and race/ethnicity (non-Hispanic white, Hispanic, other). Confidence intervals $(95 \%)$ are shown.

that those who matured through their teen years in the environment of a comprehensive tobacco control programme had a lower rate of ever experimenting with cigarettes (reported as young adults) than those in earlier cohorts.

\section{California versus the rest of the USA}

Trends in the percentage of current smokers are reported separately for young adult residents of California and for those residing in the remaining US states using CPS data (fig 4). Prevalence among California young adults was much lower in all survey periods than for those in the rest of the USA; the latter remained constant at around $22 \%$ over the entire period. California young adult prevalence also remained relatively unchanged $(\sim 18-19 \%)$ through the 1990 s, and then it declined to $15.5 \%$ in $2001 / 02$, a significant reduction of $18 \%$ from the 1998/99 level.

\section{DISCUSSION}

The evaluation plan for the ongoing California Tobacco Control Program included large population based surveys that allowed assessment of whether the programme was associated with a major long term decline of smoking in young people. During the 1990s, California's youngest adolescents (12-13 years) showed a pronounced decrease in ever experimenting with cigarette smoking (even a few puffs). For the youngest adolescents, this declining trend was evident from the beginning of the surveillance system and continued through the latest survey. Because the start of the decline was delayed in the older groups, we believe that the decline for the youngest group may have started coincidentally with the beginning of the programme. These data suggest that the influences against smoking in California throughout the 1990s may have been mainly effective in preventing new cohorts of adolescents from experimenting as they entered the age window that defines smoking initiation in recent times. The decline in the rate of ever smoking among 18-24 year olds between 1999 and 2002 suggests that people who matured in an era of tobacco control maintained a lower level of smoking initiation into young adulthood. The young adults in 2002 were $6-11$ years of age at the start of California's Tobacco Control Program. Further, the young adult prevalence data from the CPS suggest that these declines were unique to California and were not present in the rest of the USA.

There are a number of possible explanations for the large decline in smoking uptake in California. The 1990s were a time of considerable change in the forces affecting tobacco use. At the start of the decade across the USA, the innovative 
cartoon character Joe Camel advertised smoking to children and youth. ${ }^{27-29}$ By mid decade, as the effectiveness of the Joe Camel campaign and increased distribution of tobacco promotional items became apparent, ${ }^{30-33}$ these marketing strategies were restricted by the 1998 Master Settlement Agreement (MSA). ${ }^{34}$ The MSA resulted from lawsuits brought by 46 states against the major tobacco companies to recover health care costs resulting from smoking.

In California, after the excise tax increase in 1989 that made its comprehensive tobacco control programme possible, other programme elements were implemented, beginning in 1990. California's mass media campaign conducted throughout the period targeted less than one third of its anti-tobacco messages at adolescents, including questioning the deceptive practices of the tobacco industry. ${ }^{14}$ Such campaigns have been shown to be successful in promoting behaviour change in adolescents in various settings. ${ }^{35}{ }^{36}$ However, the major portion of the media campaign messages focused on cessation, and educating the public about the dangers of secondhand smoke and the general health consequences of smoking. These other messages may also have led to a change in adolescent smoking behaviour by denormalising tobacco use.

Further, throughout the 1990s California smokers were increasingly restricted regarding where they could smoke. In 1995, smoking was banned in most workplaces (including all high schools); bars and taverns were required to be smoke-free in 1998. Throughout the 1990s, Californians increasingly adopted smoke-free homes, ${ }^{37}$ probably as a result of their increasing recognition of the health dangers of secondhand smoke as explained by the media campaign. California also passed legislation that made it increasingly difficult for adolescents to purchase cigarettes. These restrictions would be expected to limit the opportunity for adolescent experimentation, as well as reduce the perception that smoking is normative.

While literature suggests that a cigarette price increase could affect adolescent smoking behaviour, ${ }^{38-40}$ it may be unlikely to influence first experimentation. ${ }^{41} 42$ The real (inflation adjusted) price of cigarettes stayed fairly stable from the start of the programme in 1990 until 1999. However, in 1999, there was a substantial price increase, both because of an additional \$0.50/pack excise tax increase approved by California voters, and as a result of a roughly $\$ 0.70 /$ pack industry price increase after the MSA. Given the timing, it is highly unlikely that cigarette price increases were a factor in the decline observed in adolescent experimentation, although they may have played a role in reducing transition to regular smoking or smoking intensity. ${ }^{43} 44$

There are several potential study limitations. Smoking behaviour is from self report, but such data are generally considered sufficiently valid in population studies of both adolescents $^{43}$ and adults. ${ }^{44}{ }^{45}$ Household surveys, such as the

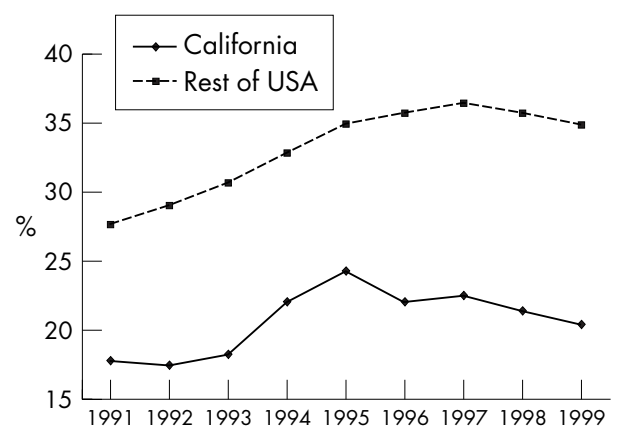

Figure 5 Monitoring the Future trends (1991-1999) in high school senior current smoking prevalence (any days in last month) for California and the rest of the USA. Reproduced from Farrelly et al, ${ }^{36}$ with permission of the author and publisher.

\section{What this paper adds}

Youth focused anti-tobacco media campaigns have been associated with declines in adolescent smoking, but whether a comprehensive tobacco control programme that included mostly general media and other non-media components might have this association has not been demonstrated.

During California's comprehensive tobacco control programme (1990-2002), a number of measures of early smoking behaviour in adolescents declined, with the decline beginning later in older age groups. Each new cohort of young adolescents showed progressively lower rates of ever puffing on a cigarette. Further, the cohort entering their teens at the beginning of the programme and who reached young adulthood by 2002 had a lower rate of ever experimenting compared to older cohorts. Finally, this decline in experimentation translated into a decline in California young adult smoking prevalence not observed in the rest of the USA.

CTS and CPS, are known to provide lower estimates of smoking behaviour than school surveys (for example, Monitoring the Future), ${ }^{46}{ }^{47}$ but all surveys compared used the same survey mode, allowing trends to be assessed. The CTS are telephone surveys with declining response rates throughout the 1990s, although the resultant samples do not appear to be biased as a result. ${ }^{19}$ The smoking behaviour trends in this study are consistent with a comparison of smoking initiation rates in two separate three year longitudinal studies of 12-15 year old California adolescent never smokers at baseline; initiation rates by follow up were higher between 1993 and 1996 than between 1996 and 1999. ${ }^{48}$ The results are further strengthened by recently-published trends from Monitoring the Future surveys (fig 5), which indicate that in recent years, smoking prevalence among California high school seniors declined more than their counterparts in the rest of the USA. ${ }^{36}$ In 1995, when prevalence peaked in California's 12th graders, prevalence in the rest of the USA was $44 \%$ higher, but by 1999 , it was $71 \%$ higher. However, future surveys will be required to further corroborate the trends documented in the present study.

In summary, the comprehensive approach used by the California Tobacco Control Program appears to have significantly reduced the likelihood of future smoking initiation among young adolescents, which has translated into lower smoking rates in later adolescence and young adulthood. The magnitude of this effect over the 13 year period appears larger than any previously reported. ${ }^{36}$ Future research will be required to assess the health effects of reduced exposure to cigarettes among these younger California birth cohorts.

\section{ACKNOWLEDGEMENTS}

This work was supported by the Tobacco Related Disease Research Program grant 12RT-0082 from the University of California. Data for the California Tobacco Surveys were collected under contracts 8997872 (1990), 92-10601 (1993), 95-23211 (1996), 98-15657 (1999), and 01-16370 (2002) from the California Department of Health Services, Tobacco Control Section, Sacramento, California.

\section{Authors' affiliations}

J P Pierce, M M White, E A Gilpin, Cancer Prevention and Control Program, Rebecca and John Moores UCSD Cancer Center, University of California, San Diego, La Jolla, California, USA

Competing interests: none declared

\section{REFERENCES}

1 Bal DG, Kizer KW, Felten PG, et al. Reducing tobacco consumption in California. JAMA 1990;264:1570-4. 
2 Tobacco Education Oversight Committee. Towards a tobacco free California Sacramento: California Department of Health Services, 1991.

3 Baver UE, Johnson TM, Hopkins RS, et al. Changes in youth cigarette use and intentions following implementation of a tobacco control program. Findings from the Florida Youth Tobacco Survey, 1998-2000. JAMA 2000;284:723-8.

4 Farrelly MC, Healton CG, Davis KC, et al. Getting to the truth: evaluating national tobacco countermarketing campaigns. Am J Public Health 2002:92:901-7

5 Hu TW, Keeler TE, Sung HY, et al. The impact of California anti-smoking legislation on cigarette sales, consumption, and prices. Tobacco Control 1995;14(suppl I):i34-8.

6 Pierce JP, Gilpin EA, Emery SL, et al. Has the California Tobacco Control Program reduced smoking? JAMA 1998;280:893-9.

7 Gilpin EA, White MM, White VM, et al. Tobacco control successes in California: a focus on young people, results from the California Tobacco Surveys, 1990-2002. La Jolla: University of California, San Diego, 2003.

8 Glynn TJ. Essential elements of school-based smoking prevention programs. J Sch Health 1989;59:181-8.

9 Taioli E, Wynder EL. Effect on the age at which smoking begins of frequency of smoking in adulthood. N Engl J Med 1991;325:968-9.

10 Breslau N, Fenn N, Peterson EL. Early smoking initiation and nicotine depencence in a cohort of young adults. Drug Alcohol Depend 1993;33:129-37.

11 Breslau N, Peterson EL. Smoking cessation in young adults: age at initiation of cigarette smoking and other suspected influences. Am J Public Health 1996;86:214-20.

12 Chen J, Millar WJ. Age of smoking initiation: implications for quitting. Health Rep 1998;9:39-46

13 Pierce JP, Gilpin EA, Emery SL, et al. Tobacco control in California: who's winning the war? An evaluation of the Tobacco Control Program, 19891996. La Jolla: University of California, San Diego, 1998.

14 Ibrahim JK, Glantz SA. Tobacco policy making in California 2001-2003: no longer finishing first, 2003, http://repositories.cdlib.org/ctcre/tcpmus/ CAPolicy2003.

15 Ling PM, Glantz SA. Why and how the tobacco industry sells cigarettes to young adults: evidence from industry documents. Am J Public Health 2002;92:908-16.

16 University of California San Diego, Social Science Data Collection. Final reports and technical documentation for the California Tobacco Surveys, 2004, http://ssdc.ucsd.edu/tobacco.

17 Keeter S, Miller C, Kohut A, et al. Consequences of reducing nonresponse in a national telephone survey. Public Opin Q 2000;64:125-48.

18 De Leeuw E, de Heer W. Trends in household survey nonresponse: a longitudinal and international comparison. In: Groves RM, Dillman DA, Eltinge JL, Little RJA, eds. Survey nonresponse. New York: John Wiley \& Sons, 2002:41-54.

19 Biener L, Garrett CA, Gilpin EA, et al. Consequences of declining survey response rates for smoking prevalence. Am J Prev Med 2004;27:254-7.

20 US Department of Commerce. Current Population Survey. Design and methodology, Technical Paper 63. Washington DC: US Department of Commerce, Bureau of the Census, 2000.

21 US Department of Health and Human Services. Reducing the health consequences of smoking: 25 years of progress. A report of the Surgeon General, 1989. Rockville, Maryland: Public Health Service, Centers for Disease Control, Office on Smoking and Health, 1989 (DHHS Publication No (CDC) 89-841 1.)

22 US Department of Health and Human Services. Preventing tobacco use among young people. A report of the Surgeon General, 1994. Atlanta, Georgia: Public Health Service, Centers for Disease Control and Prevention, Office on Smoking and Health, 1994 (US Government Printing Office Publication No S/N 017-001-00491-0.).
23 Choi WC, Gilpin EA, Farkas AJ, et al. Determining the probability of future smoking among adolescents. Addiction 2001;96:313-23.

24 Pierce JP, Gilpin EA. How long will today's new adolescent smokers be addicted to cigarettes? Am J Public Health 1996:86:253-6.

25 Research Triangle Institute. SuDaaN. Version 8.0. Research Triangle Park, North Caroline: Research Triangle Institute, 2002.

26 Effron B. The jackknife, the bootstrap and other resampling plans: CMBS Regional Conference Series in Applied Mathematics38. Philadelphia: Society for Industrial and Applied Mathematics, 1982

27 Di Franza JR, Richards JW, Paulman PM, et al. RJR Nabisco's cartoon camel promotes camel cigarettes to children. JAMA 1991;266:3149-53.

28 Fischer PM, Schwartz MP, Richards JW, et al. Brand logo recognition by children aged 3 to 6 years. Mickey Mouse and Old Joe the Camel. JAMA 1991;266:3145-8.

29 Pierce JP, Gilpin E, Burns DM, et al. Does tobacco advertising target young people to start smoking: evidence from California. JAMA 1991;266:3154-8.

30 Cohen JB. Playing to win: marketing and public policy at odds over Joe Camel. J Public Policy Marketing 2000;19:155-67.

31 Pierce JP, Choi WS, Gilpin EA, et al. Tobacco industry promotion of cigarettes and adolescent smoking. JAMA 1998;279:511-15.

32 Sargent JD, Dalton $M$, Beach $M$, et al. Effect of cigarette promotions on smoking uptake among adolescents. Prev Med 2000;30:320-7.

33 Biener L, Siegel M. Tobacco marketing and adolescent smoking: more support for a causal inference. Am J Public Health 2000;90:407-11.

34 National Association of Attorneys General. Tobacco settlement summary; 1998. http://www.naag.org/glance.htm.

35 Worden JK, Flynn BS, Solomon $\sqcup$, et al. Using mass media to prevent cigarette smoking among adolescent girls. Health Educ Q 1996;23:453-68.

36 Farrelly MC, Niederdeppe J, Yarsevich J. Youth tobacco prevention mass media campaigns; past, present, and future directions. Tobacco Control 2003; 12(suppl I):i35-47.

37 Gilpin EA, Farkas AJ, Emery SL, et al. Clean indoor air: advances in California, 1990-1999. Am J Public Health 2002;92:785-91.

38 Lewit EM, Coate D, Grossman M. The effect of government regulation on teenage smoking. J Law Econ 1981;24:545-69.

39 National Cancer Institute. The impact of cigarette excise taxes on smoking among children and adults. Summary report of a National Cancer Insititute expert panel. Bethesda, Maryland: National Cancer Institute, Division of Cancer Prevention and Control, Cancer Control Science Program, 1993.

40 Gruber J. Youth smoking in the US: prices and policies. NBER Working Paper, Vol W7506. Cambridge, Massachusetts, 2000

41 Emery S, White MM, Pierce JP. Does cigarette price influence adolescent experimentation? J Health Econ 2001;20:261-70.

42 Liang L, Chaloupka FJ. Differential effects of cigarette price on youth smoking intensity. Nicotine Tob Res 2002;4:109-14.

43 Caraballo RS, Giovino GA, Pechacek TF. Self-reported cigarette smoking versus serum cotinine among U.S. adolescents. Nicotine Tob Research 2004;6:19-25.

44 Hatziandreu EJ, Pierce JP, Fiore MC, et al. The reliability of self-reported cigarette consumption in the United States. Am J Public Health 1989;79:1020-3.

45 Gilpin EA, Pierce JP, Cavin SW, et al. Estimates of population smoking prevalence: self vs. proxy reports of smoking status. Am J Public Health 1994:84:1576-9.

46 Kann L, Brener ND, Warren CW, et al. An assessment of the effect of data collection setting on the prevalence of health-risk behaviors among adolescents. J Adol Health 2002;31:327-35.

47 Biglan M, Gilpin EA, Rohrbach LA, et al. Is there a simple correction factor for comparing adolescent tobacco use estimates from school- and home-based surveys. Nicotine Tob Research 2004;6:427-37.

48 Gilpin EA, Pierce JP. How have smoking risk factors changed with recent declines in adolescent smoking? Addiction 2005;100:117-25.

\section{The Lighter Side}

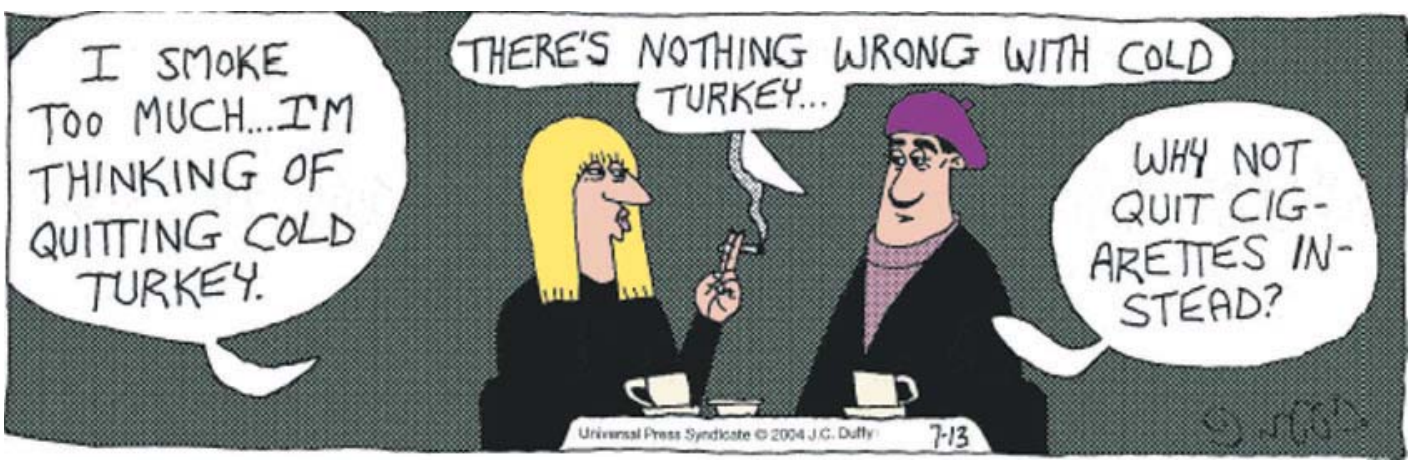

(c) The Fusco Brothers, by J C Duffy, 2004. UNIVERSAL PRESS SYNDICATE. Repreinted with permission. All rights reserved. 